\title{
Molecular detection of Rickettsia, Borrelia, and Babesia species in Ixodes ricinus sampled in northeastern, central, and insular areas of Italy
}

\author{
Lyda R. Castro ${ }^{1} \cdot$ Simona Gabrielli $^{2}$ - Albertina Iori $^{2}$ • \\ Gabriella Cancrini
}

Received: 4 December 2014/ Accepted: 5 March 2015

(C) Springer International Publishing Switzerland 2015

\begin{abstract}
The aim of the present study was to provide insight into the diversity of tickborne pathogens circulating in Italy, carried/transmitted by Ixodes ricinus, one of the most abundant tick species in the country. A total of 447 specimens sampled in five areas of northeastern, central and insular Italy were analysed by polymerase chain reaction and sequencing for the presence of rickettsiae, borreliae and babesiae. Several rickettsial species of the spotted fever group of zoonotic concern and other zoonotic pathogens were found, such as Borrelia burgdorferi s.s., Borrelia afzelii, Borrelia garinii, and Babesia venatorum. These findings confirm a wide distribution of tick-borne bacterial and protozoan species in Italy, and highlight the sanitary importance of I. ricinus, often recorded as feeding on humans.
\end{abstract}

Keywords Rickettsia spp. B Borrelia spp. B Babesia venatorum · Italy · PCR

\section{Introduction}

Ticks (Acari: Ixodidae) are among the most important vectors of diseases in temperate climates (Heyman et al. 2010). In Europe, a wide range of tick-borne pathogens, including viruses, bacteria, and protozoa can cause diseases in both animals and humans. Moreover, some tick-borne pathogens are recognized as important zoonotic pathogens (Sparagano et al. 1999).

Rickettsiae, for example, are intracellular bacteria maintained in nature by Ixodid ticks through trans-stadial and trans-ovarial transmission; therefore their geographical distribution coincides to the distribution of the carrier ticks (Parola and Raoult 2001). Several

Lyda R. Castro

lydaraquelcastro@hotmail.com

1 Grupo de Investigación Evolución, Sistemática y Ecología Molecular, Lab 2, Intropic, Universidad del Magdalena, Cra 32 No. 22 - 08, Santa Marta, Colombia

2 Dip. di Sanità Pubblica e Malattie Infettive, Università "Sapienza”, Rome, Italy 
species, like Rickettsia conorii in Europe, are well-known causative agents of diseases. However, molecular approaches had enabled recent identification of other rickettsiae of the spotted fever group of interest to animal and human health (Oteo and Portillo 2012). Of these, Rickettsia helvetica, Rickettsia monacensis, Rickettsia raoultii, Rickettsia aeschlimannii and Rickettsia massiliae have been reported in Ixodes ricinus (Parola et al. 2013).

Also, spirochetes of the complex Borrelia burgdorferi s.l., etiological agents of Lyme borreliosis (LB), are transmitted mainly by I. ricinus (Hengge et al. 2003), and are reported as endemic in Italy (Lindgren and Jaenson 2006). Several studies, especially in northern regions, have confirmed the presence of the disease (Cinco et al. 2004; Pajoro et al. 2010; Pistone et al. 2010; Ravagnan et al. 2010).

Concerning protozoa, many species of the genus Babesia, which can cause malaria-like syndrome in animals and humans, are tick-transmitted and, in Europe, most of them have $I$. ricinus as the main vector (Duh et al. 2001; Hilpertshauser et al. 2006; Bonnet et al. 2007). In Italy, babesioses affects from 2.5 to $30.4 \%$ of livestock, pets and wild animals (Cringoli et al. 2002; Cancrini et al. 2007; Pietrobelli et al. 2007; Torina and Caracappa 2007; Cassini et al. 2009; Moretti et al. 2009), and recent studies revealed evidence of these protozoa in about $2.5 \%$ of ticks sampled from central and northern Italy (Iori et al. 2010). As a confirmation of their zoonotic importance, about $19 \%$ of people living in the same areas showed reactivity to different babesial antigens (Gabrielli et al. 2014).

The aim of this study was to add new knowledge to the complex puzzle of pathogens transmitted by I. ricinus through the analysis of specimens collected in areas of Italy that had been scarcely or not at all studied previously.

\section{Materials and methods}

\section{Samples}

Host-seeking ticks were collected during 2007-2010 from the environment in selected sites of northeastern (Belluno), central (Perugia, Rieti) and insular (Pianosa and Capri) areas of Italy (Fig. 1). Sampling was carried out using the dragged woollen blanket technique (Mannelli et al. 1999), in a restricted area of 1 ha, over six sessions. Sites were chosen on the basis of suitable biotope structures and on the previous descriptions of tick occurrence, with the exception of Capri for which no previous data were available. Morphological identification was performed by microscopy, recording the developing stage and using morphological keys (Manilla 1998; Iori et al. 2005).

\section{DNA extraction}

Genomic DNA was extracted from single adults, single nymphs, and pools of larvae $(\mathrm{n}=5)$ by the phenol-chloroform method (Favia et al. 2001). Briefly, DNA was extracted by grinding the ticks in TES buffer/Tris- $\mathrm{HCl} 50 \mathrm{mM}$, EDTA $1 \mathrm{mM}$, sucrose $15 \%$, pH 8 , after abdomen incision. Proteinase $\mathrm{K}$ was added at a final concentration of $1 \mathrm{mg} / \mathrm{mL}$, and samples were incubated overnight at $42{ }^{\circ} \mathrm{C}$. Phenol-chloroform was used for further DNA isolation and DNA was ethanol-precipitated. The pellet was resuspended in $50 \mu \mathrm{L}$ of double-distilled water. Finally, DNA quality and concentration was verified by electrophoresis using $1 \%$ agarose gels. 


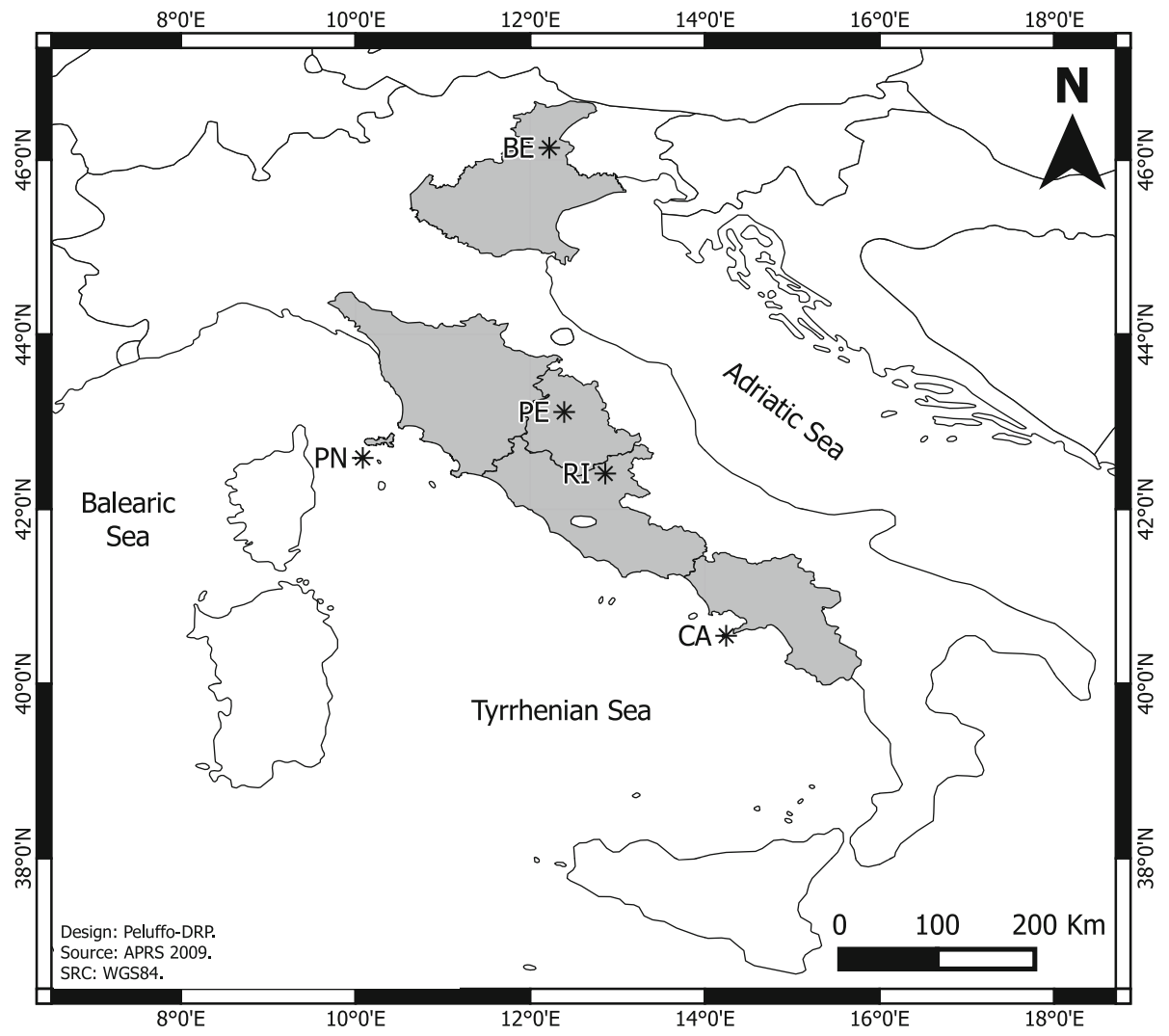

Fig. 1 Map of Italy showing the regions and areas where ticks were collected: BE (Belluno), PE (Perugia), RI (Rieti), PI (Pianosa), CA (Capri)

\section{PCR, and DNA sequence analysis}

DNA samples were screened for the gltA gene of Rickettsia spp., the $18 S$ rRNA gene of Babesia spp. and the flagellin gene (Fla) of Borrelia spp. using primers and conditions previously described (Table 1). Borrelia sp. positive samples were further amplified with species-specific 16S identification primers (Marconi and Garon 1992). Amplifications were performed in a volume of $25 \mu \mathrm{L}$ containing: $0.2 \mu \mathrm{L}$ BIO-X-ACT Short DNA Polymerase (Bioline, Italy), $0.5 \mu \mathrm{L}$ of each primer $(50 \mathrm{mM}), 3 \mu \mathrm{L}$ of template $(25 \mathrm{ng} / \mu \mathrm{L}), 2.5 \mu \mathrm{L}$ of dNTP $(10 \mathrm{mM}), 2 \mu \mathrm{L}$ of $\mathrm{MgCl}_{2}(50 \mathrm{mM}), 2.5 \mu \mathrm{L}$ PCR Buffer $(10 \times)$ and $13.8 \mu \mathrm{L}$ of $\mathrm{ddH}_{2} \mathrm{O}$. All the PCR reactions included positive controls that had been identified by our group in previous works (Cassini et al. 2009; Iori et al. 2002; Veronesi et al. 2006), and negative (sterile deionized water) controls.

Amplifications were followed by $2 \%$ agarose-gel electrophoresis and were visualized with GelRed ${ }^{\circledR}$ (Biotium, Hayward, USA) under UV-light. PCR products were purified with SureClean purification Kit (Bioline, Italy) and sequenced by Eurofins MWG Operon (Ebersberg, Germany). Sequence comparisons were performed with the BLAST tool provided by the National Center for Biotechnology (http://blast.ncbi.nlm.nih.gov/). 


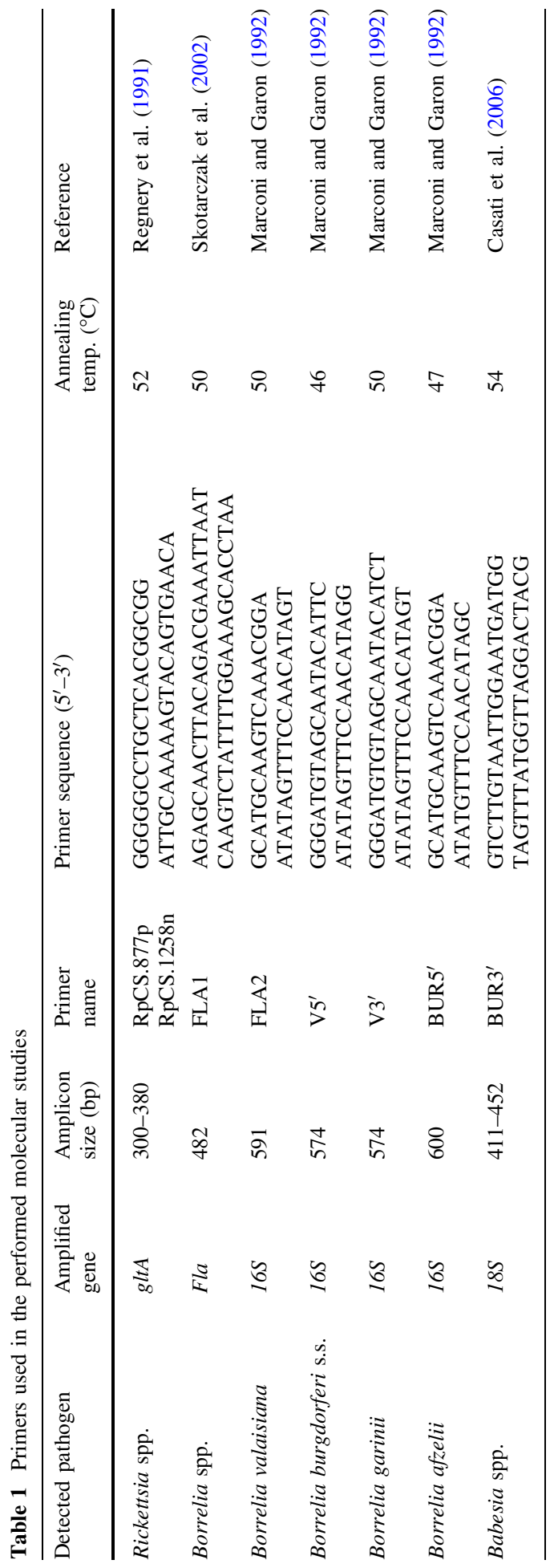




\section{Phylogenetic analysis}

In order to support BLAST amplifications phylogenetic trees were constructed. Nucleotide alignments were performed using MUSCLE (Edgar 2004) as implemented in MEGA V.5 (Tamura et al. 2011). The model of molecular evolution was calculated using jModelTest 2 (Darriba et al. 2012), and Bayesian analyses were performed using MrBayes (Ronquist and Huelsenbeck 2003). Two independent runs of 2,000,000 generations were performed, with trees sampled every 100 generations, $25 \%$ of the trees were discarded as burnin. Convergence was validated by the standard deviation of split frequencies $(<0.01)$, by plotting the likelihood values over time, and by using the sump command in MrBayes. The percentage of trees recovering a particular clade was used as a measure of that clade's posterior probability (Huelsenbeck and Ronquist 2001).

\section{Results}

Among the ticks collected a total of 447 (341 adults, 77 nymphs and 29 larvae) were morphologically identified as $I$. ricinus. Altogether 86 ticks (82 adults, 4 nymphs) $(19.23 \%)$ showed products of the expected length in the PCR for Rickettsia spp. (Table 2). Sequencing of rickettsial gltA products and BLAST comparisons with the GenBank database revealed 99-100\% identity with the following rickettsial species: $R$. monacensis in 5 isolates from Rieti (e.g. KC996728.1, JX04639.1, KJ663735.1), R. helvetica in 2 isolates from Rieti and 1 from Belluno (KF447530.1, JX040636.1), $R$. massiliae in 2 isolates from Perugia (KC428030.1). Samples from Pianosa (6 isolates) matched to both $R$. raoultii (e.g. KF003009.1, KC428020.1), and $R$. aeschlimanni (e.g. AY259084.1, HQ335153.1). There were no positive samples in Capri Island. The phylogenetic tree constructed with the Rickettsia sequences confirmed the BLAST results, and the different sequences amplified from I. ricinus in this study clustered with expected species of the spotted fever group of the genus Rickettsia (Fig. 2).

Concerning Borrelia, 17/447 specimens (3.8\%), all adults, were infected with $B$. burgdorferi DNA (Table 2). The sequences obtained showed a nucleotide identity of $99 \%$ to members of the B. burgdorferi s.l. Unfortunately, the sequenced Fla region did not allow a more detailed identification, because, for the same product, we obtained $99 \%$ identity with more than one species of the complex. Figure $3 \mathrm{a}$ shows the phylogenetic tree

Table 2 Prevalence of investigated microorganisms in I. ricinus ticks collected from different regions of Italy

\begin{tabular}{|c|c|c|c|c|}
\hline \multirow[t]{3}{*}{ Sampling area } & \multicolumn{4}{|l|}{ Ixodes ricinus } \\
\hline & \multirow[t]{2}{*}{ Examined no. } & \multicolumn{3}{|l|}{ Infected by } \\
\hline & & Rickettsia no. (\%) & Borrelia no. (\%) & Babesia no. (\%) \\
\hline Belluno & 148 & $6(4)$ & $2(1.35)$ & $1(0.68)$ \\
\hline Perugia & 76 & $25(32.89)$ & $15(19.73)$ & $0(0)$ \\
\hline Rieti & 98 & $22(22.44)$ & $0(0)$ & $0(0)$ \\
\hline Pianosa & 35 & $28(80)$ & $0(0)$ & $0(0)$ \\
\hline Capri & 90 & $0(0)$ & $0(0)$ & $0(0)$ \\
\hline Total & 447 & $86(19.23)$ & $17(3.8)$ & $1(0.22)$ \\
\hline
\end{tabular}




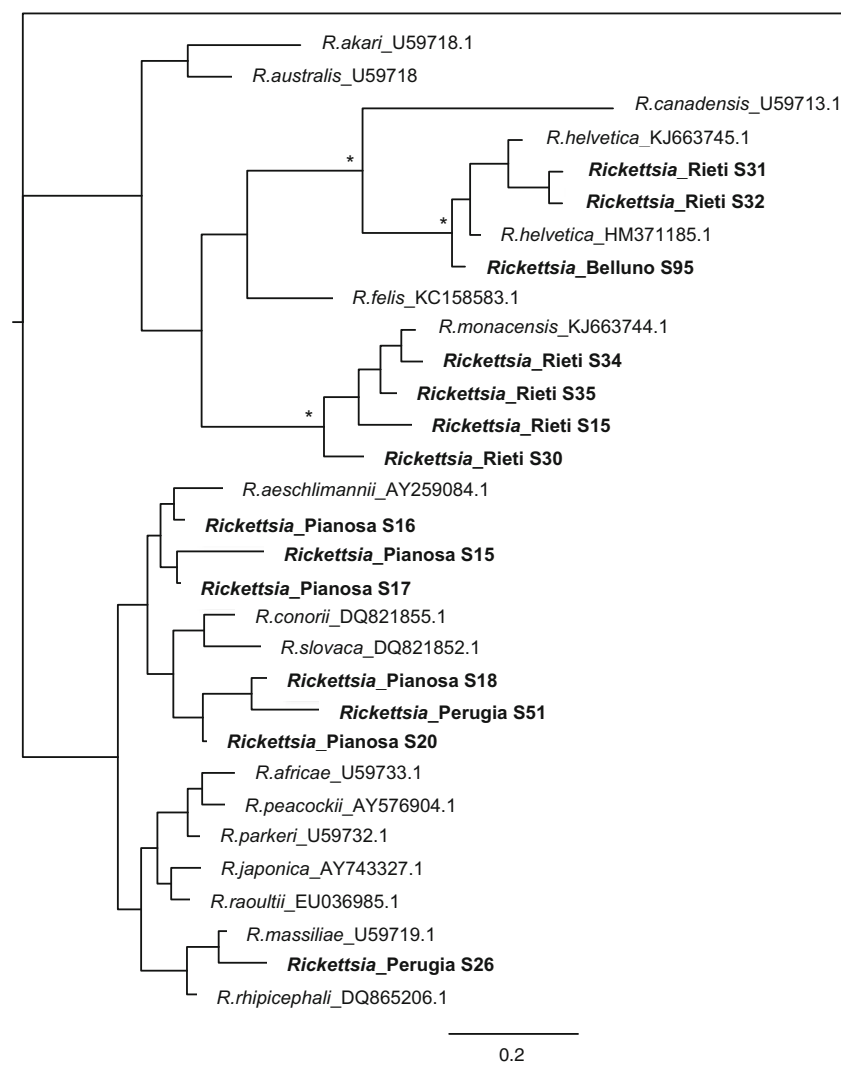

R.bellii_DQ146481.1

Fig. 2 Topology of the Bayesian phylogenetic analysis including Rickettsia spp. sequences from this study (highlighted), and others downloaded from GenBank (coded with each accession number). Asterisks represent posterior probabilities that were $>0.95$

reconstructed including Borrelia Fla sequences. Some of our sequences group with strong posterior probability with Borrelia afzelii, however, most of the groupings are not well supported. Instead, further PCR amplifications with $16 S$ species-specific primers allowed us to identify, in the two positive ticks from Belluno, B. afzelii and B. burgdorferi s.s., and, in the 15 specimens from Perugia, B. burgdorferi s.s. $(\mathrm{n}=1)$, B. afzelii $(\mathrm{n}=6)$, Borrelia valaisiana $(\mathrm{n}=3)$, and Borrelia garinii $(\mathrm{n}=5)$.

Babesial DNA was detected only in 1 adult specimen $(0.22 \%)$ (Table 2). Unidirectional sequencing results of the $18 S$ rRNA gene product revealed $100 \%$ identity with Babesia venatorum (formerly Babesia sp. EU1) (accession no. KJ663730.1). The phylogenetic analysis also groups the species from this study with B. venatorum with high percent posterior probability (Fig. 3b).

No specimens were found simultaneously infected by more than one pathogen. All the sequences were deposited in GenBank under accession numbers: KM198331-KM198346. 
A

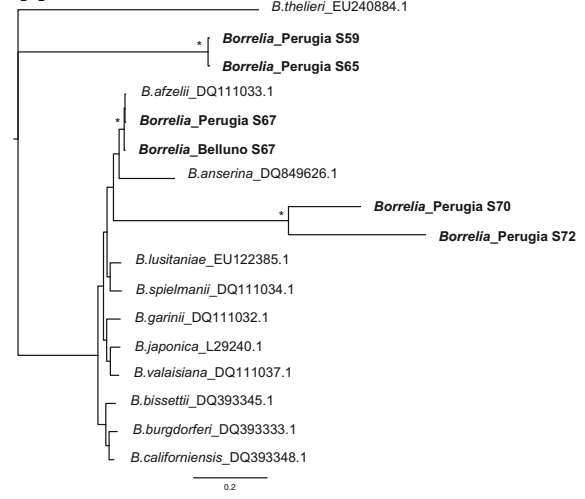

B

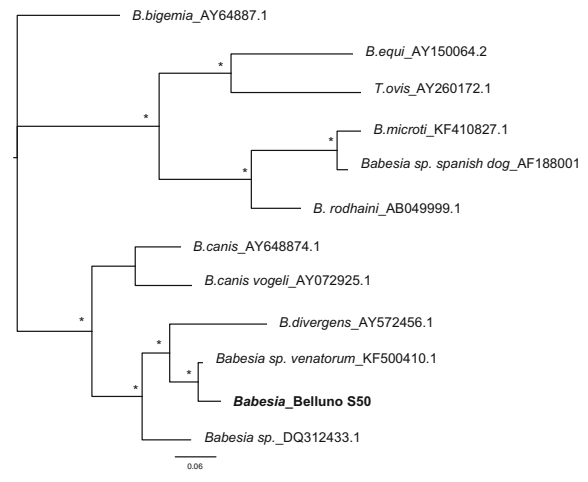

Fig. 3 Topology of the Bayesian phylogenetic analyses including Borrelia spp. (a) and Babesia spp. (b) sequences from this study (highlighted), and others downloaded from GenBank (coded with each accession number). Asterisks represent posterior probabilities that were $>0.95$

\section{Discussion}

Our results confirmed the presence of several Rickettsia species, and other zoonotic pathogens such as: B. burgdorferi s.s., B. afzelii, B. garinii, and B. venatorum, in I. ricinus sampled in different regions of Italy.

Rickettsiae were the most frequently found pathogenic agents, with six species found ( $R$. monacensis, $R$. helvetica, $R$. massiliae, $R$. raoultii and $R$. aeschlimanni). It has been reported that clinical and epidemiological features vary depending on the rickettsial species involved in the disease (Raoult 2004; Parola et al. 2005). Thus, physicians should be aware of the different Ricketsia species that can be transmitted, and should be well trained on the clinical features of the corresponding infections in order to intervene, when needed, with the appropriate treatment. In Africa, for example, $R$. conorii and Rickettsia africae are prevalent, but clinical findings regarding patients infected with these agents are different. Patients infected with $R$. africae exhibit multiple eschars more commonly and exhibit a generalized rash less commonly than do patients infected by $R$. conorii. Moreover, vesicular eruption can be caused by $R$. africae but not by $R$. conorii (Raoult et al. 2001).

Concerning borreliae, the number of positive ticks was low (only $3.8 \%$ ), without positive samples from Rieti or the two islands. Our study confirms the presence of $B$. burgdorferi complex in I. ricinus from central and northeastern areas of Italy (Perugia and Belluno), with an infection rate of $20 \%$ for the area of Perugia, which is similar to that reported in the Po River Valley (18\%) (Pistone et al. 2010), and in northern Italian provinces $(17.6 \%$ ) (Ravagnan et al. 2010). In addition, the $16 S$ species-specific primers allowed us to identify, in the Perugia area, four genomic groups of the B. burdorferi s.l. complex: B. valaisiana, B. garinii, B. afzelii and B. burgorferi s.s., from which the last 3 species have been confirmed to be pathogenic to humans (Rauter and Hartung 2005), and are associated with different clinical symptoms of LB. Indeed, B. afzelii mainly match with skin manifestations and $B$. burgdorferi s.s with Lyme arthritis, whereas $B$. garinii is the only species correlated to neuroborreliosis (Balmelli and Piffaretti 1995; Van Dam et al. 1993). Our findings stress the poor benefits of the Fla gene to identify Borrelia species, and add new knowledge about the geographic distribution of the genospecies of the $B$. 
burgdorferi complex that is not only of ecological and epidemiological interest, but also of clinical relevance.

Only one tick from Belluno was infected with B. venatorum, the species firstly identified in splenectomised patients living in Italy and in Austria (Herwaldt et al. 2003), and previously found in I. ricinus collected in northern-northeastern Italy with and infection rate of $0.85 \%$, similar to what we found (Cassini et al. 2010).

In conclusion, the present study evidenced a wide distribution of several bacterial and protozoan tick-borne pathogens. Therefore I. ricinus, one of the most abundant tick species in Italy, confirms to be a fearful possible source of infection.

Acknowledgments Authors are grateful to Mrs G. Croce and Mr A. Giacomi for the excellent technical assistance and to Prof. D. Piergili Fioretti and P. Calderini for providing some tick samples. This work was financially supported by the Italian Ministry of University and Research (PRIN, Prot. 2004075927_002). We also thank the Erasmus Mundus program of the EulaLinks consortium for the fellowship given to Lyda Castro.

Conflict of interest The authors declare that they have no conflict of interest.

\section{References}

Balmelli T, Piffaretti JC (1995) Association between different clinical manifestations of Lyme disease and different species of Borrelia burgdorferi sensu lato. Res Microbiol 146:329-340

Bonnet S, Jouglin M, L'Hostis M, Chauvin A (2007) Babesia sp. EU1 from roe deer and transmission within Ixodes ricinus. Emerg Infect Dis 13:1208-1210

Cancrini G, Calderini P, Gabrielli S, Scaramozzino P, Iori A (2007) Babesiosis and theileriosis: first evidence in domestic and wild animals in Lazio region (Central Italy). Parassitologia 49:80

Casati S, Sager H, Gern L, Piffaretti JC (2006) Presence of potentially pathogenic Babesia sp. for human in Ixodes ricinus in Switzerland. Ann Agric Environ Med 13:65-70

Cassini R, Zanutto S, Frangipane di Regalbono A, Gabrielli S, Calderini P, Moretti A, Tampieri MP, Pietrobelli M (2009) Canine piroplasmosis in Italy: epidemiological aspects in vertebrate and invertebrate hosts. Vet Parasitol 165:30-35

Cassini R, Bonoli C, Montarsi F, Tessarin C, Marcer F, Galuppi R (2010) Detection of Babesia EU1 in Ixodes ricinus ticks in northern Italy. Vet Parasitol 171:151-154

Cinco M, Barbone F, Grazia Ciufolini M, Mascioli M, Anguero-Rosenfeld M, Stefanel P et al (2004) Seroprevalence of tick-borne infections in forestry rangers from Northeastern Italy. Clin Microbiol Infect 10:1056-1061. doi:10.1111/j.1469-0691.2004.01026.x

Cringoli G, Otranto D, Testini G, Buono V, Di Giulio G, Traversa D, Lia R, Rinaldi L, Veneziano V, Piccini V (2002) Epidemiology of bovine tick-borne diseases in southern Italy. Vet Res 33:421-428

Darriba D, Taboada GL, Doallo R, Posada D (2012) jModelTest 2: more models, new heuristics and parallel computing. Nat Methods 9:772

Duh D, Petrovec M, Avsic-Zupanc T (2001) Diversity of Babesia infecting European sheep ticks (Ixodes ricinus). J Clin Microbiol 39:3395-3397

Edgar RC (2004) MUSCLE: multiple sequence alignment with high accuracy and high throughput. Nucl Acids Res 32:1792-1797

Favia G, Cancrini G, Carfì A, Grazioli D, Lillini E, Iori A (2001) Molecular identification of Borrelia valaisiana and HGE-like Ehrlichia in Ixodes ricinus ticks sampled in North Eastern Italy. Parassitologia 43:143-146

Gabrielli S, Calderini P, Cassini R, Galuppi R, Tampieri MP, Pietrobelli M, Cancrini G (2014) Human exposure to piroplasms in central and northern Italy. Vet Ital 50(1):41-47

Hengge UR, Tannapfel A, Tyring SK, Erbel R, Arendt G, Ruzicka T (2003) Lyme borreliosis. Lancet Infect Dis 3:489-500. doi:10.1016/S1473-3099(03)00722-9

Herwaldt BL, Cacció S, Gherlinzoni F, Aspock H, Slemenda SB, Piccaluga P, Martinelli G, Edelhofer R, Hollenstein U, Poletti G, Pampiglione S, Loschenberger K, Tura S, Pieniazek NJ (2003) Molecular characterization of a non-Babesia divergens organism causing zoonotic babesiosis in Europe. Emerg Infect Dis 9:942-948 
Heyman P, Cochez C, Hofhuis A, van der Giessen J, Sprong H, Porter SR, Losson B, Saegerman C, DonosoMantke O, Niedrig M, Papa A (2010) A clear and present danger: tick-borne diseases in Europe. Expert Rev Anti Infect Ther 8:33-50

Hilpertshauser H, Deplazes P, Schnyder M, Gern L, Mathis A (2006) Babesia spp. identified by PCR in ticks collected from domestic and wild ruminants in southern Switzerland Appl. Environ Microbiol 72:6503-6507

Huelsenbeck JP, Ronquist F (2001) MRBAYES: Bayesian inference of phylogeny. Bioinformatics 17:754-755

Iori A, Grazioli D, Gabrielli S, Cancrini G (2002) Molecular detection of HGE-like Ehrlichia and four genomic groups of Borrelia burgdorferi s.l. in Ixodes ricinus ticks sampled in Belluno-Feltre areas. Parassitologia 44(Suppl. 1):87

Iori A, Di Giulio A, De Felice S (2005) Zecche d'Italia. In: Crignoli G (ed) Zecche. Rolando, Napoli, pp 1-199

Iori A, Gabrielli S, Calderini P, Moretti A, Pietrobelli M, Tampieri MP, Galuppi R, Cancrini G (2010) Tick reservoirs for piroplasms in central and northern Italy. Vet Parasitol 170:291-296

Lindgren E, Jaenson TGT (2006) Lyme borreliosis in Europe: influences of climate and climate change, epidemiology, ecology and adaptation measures. WHO Regional Office for Europe, Copenhagen

Manilla G (1998) Fauna d'Italia, Acari Ixodida. Edizioni Calderini, Bologna 280 pp

Mannelli A, Cerri D, Buffrini L, Rossi S, Rosati S, Arata T, Innocenti M, Grignolo MC, Bianchi G, Iori A, Tolari F (1999) Low risk of Lyme borreliosis in a protected area on the Tyrrhenian coast, in central Italy. Eur J Epidemiol 15:371-377

Marconi RT, Garon CF (1992) Development of polymerase chain reaction primer sets for diagnosis of Lyme disease and for species-specific identification of Lyme disease isolates by $16 \mathrm{~S}$ rRNA signature nucleotide analysis. Clin Microbiol 30(11):2830-2834

Moretti A, Mangili V, Salvatori R, Maresca C, Scoccia E, Torina A, Moretta I, Gabrielli S, Tampieri MP, Pietrobelli M (2009) Prevalence and diagnosis of Babesia and Theileria infections in horses in Italy: a preliminary study. Vet J. doi:10.1016/j.tvj1.2009.03.021

Oteo J, Portillo A (2012) Tick-borne rickettsioses in Europe. Ticks Tick Borne Dis 3:270-277

Pajoro M, Pistone D, Epis S, Sassera D, Montagna M, Luzzago C, Lanfanchi P, Vigano R, Cerutti MC, Vicari N, Fabbi M, Bandi C (2010) A survey for Bacterial pathogens associated with Ixodes ricinus in north-western Italy. SOIPA XXVI Abstracts. Parassitologia 52(1-2):178

Parola P, Raoult D (2001) Ticks and tickborne bacterial diseases in humans: an emerging infectious threat. Clin Infect Dis 32:897-928

Parola P, Paddock CD, Raoult D (2005) Tick-borne rickettsioses around the world: emerging diseases challenging old concepts. Clin Microbiol Rev 18:719-756

Parola P, Paddock CD, Socolovschi C, Labruna MB, Mediannikov O, Kernif T et al (2013) Update on tickborne rickettsioses around the world: a geographic approach. Clin Microbiol Rev 26:657-702. doi:10. 1128/CMR.00032-13

Pietrobelli M, Cancrini G, Moretti A, Tampieri MP (2007) Animal babesiosis: an emerging zoonosis also in Italy? Parassitologia 49:33-38

Pistone D, Pajoro M, Fabbi M, Varari N, Marone P, Genchi C, Novati S, Sassera D, Epis S, Bandi C (2010) Lyme Borreliosis, Po River Vallley, Italy. Emerg Infect Dis 16(8):1289-1291

Raoult D (2004) A new tick-borne rickettsiosis in the USA. Clin Infect Dis 38:812-813

Raoult D, Fournier PE, Fenollar F et al (2001) Rickettsia africae, a tick-borne pathogen in travelers to subSaharan Africa. N Engl J Med 344:1504-1510

Rauter C, Hartung T (2005) Prevalence of Borrelia burdorferi Sensu lato genospecies in Ixodes ricinus ticks in Europe: a metaanalysis. Appl Envirn Microbiol 71(11):7203-7216

Ravagnan S, Montarsi F, Porcellato R, Ariani P, Cassini R, Granato A, Capelli G (2010) Borrelia burgdorferi genospecies in Ixodes ricinus ticks form Lyme borreliosis endemic area of Italy. SOIPA XXVI Abstracts. Parassitologia 52(1-2):180

Regnery RL, Spruill CL, Plikaytis BD (1991) Genotypic identification of rickettsiae and estimation of interspecies sequence divergence for portions of two rickettsial genes. J Bacteriol 173:1576-1589

Ronquist F, Huelsenbeck J (2003) MrBayes 3: Bayesian phylogenetic inference under mixed models. Bioinformatics 19:1572-1574

Skotarczak B, Wodecka B, Hermanowska-Szpakowicz T (2002) Sensitivity of PCR method for detection of DNA of Borrelia burgdorferi sensu lato in different isolates. Prz Epidemiol 56:73-79

Sparagano OAE, Allsopp MTEP, Mank RA, Rijpkema SGT, Figueroa JV, Jongejan F (1999) Molecular detection of pathogen DNA in ticks (Acari: Ixodidae): a review. Exp Appl Acarol 23:929-960 
Tamura K, Peterson D, Peterson N, Stecher G, Nei M, Kumar S (2011) MEGA5: molecular evolutionary genetics analysis using maximum likelihood, evolutionary distance, and maximum parsimony methods. Mol Biol Evol 28:2731-2739

Torina A, Caracappa S (2007) Babesiosis in Italy: an overview. Parassitologia 49:23-28

Van Dam HK, Vos K, Widjojokusumo A, De Jongh BM, Spanjaard L, Ramselaar ACP, Kramer MD, Dankert J (1993) Different genospecies of Borrelia burgdorferi are associated with distinct clinical manifestations of Lyme borreliosis. Clin Infect Dis 17:708-717

Veronesi F, Rapicetta S, Gabrielli S, Iori A, Diaferia M, Piergili Fioretti D (2006) Preliminary data on the distriburion of Rickettsia rickettsia and Rickettsia conorii in Umbria region. Parassitologia 48:328 